Mycologia, 81(4), 1989, pp. 643-646.

(C) 1989, by The New York Botanical Garden, Bronx, NY 10458-5126

\title{
A TRICHOMYCETE-LIKE FOSSIL FROM THE TRIASSIC OF ANTARCTICA
}

JAMES F. WHITE, JR.

Department of Biology, Auburn University at Montgomery, Montgomery, Alabama 36193

\author{
AND \\ THOMAS N. TAYLOR \\ Department of Botany and Byrd Polar Research Center, The Ohio State University, \\ Columbus, Ohio 43210
}

Fungi, particularly the lower fungi, are usually considered to be primitive organisms, despite the fact that almost nothing is known about their evolutionary histories. This dearth of knowledge may be rectified, in part, by acquiring information on the diversity of fungi in the fossil record. This task has proven to be a slow process; however, data on fossil fungi are slowly accummulating (e.g., Kidston and Lang, 1921; Davis and Leisman, 1962; Dilcher, 1965; Stubblefield and Taylor, 1983; White and Taylor, 1988; Osborn et al, 1989). Although a nucleus of information on fossil fungi is available, evolutionary biologists rarely incorporate such data into meaningful evolutionary scenarios. As our knowledge of fossil fungi increases, studies which rely on fossil data, like that by Pirozynski (1976) where evolutionary schemes are proposed to explain patterns of geographic distribution and host ranges of various fungal groups, may represent a valuable contribution to development of an understanding of the history of fungi. However, at the present time some groups of fungi are completely unknown in the fossil record. Among these unknown groups are fungi placed in the class Trichomycetes of the Zygomycotina.

In a recent study of silicified peat deposits collected from the Fremouw formation of the Beacon Supergroup in Antarctica, specimens which resemble extant members of the Trichomycetes were found. This formation is considered to contain fossils of Early-Middle Triassic age (White and Taylor, 1989). Light microscope slides were prepared from cellulose acetate peels of rock surfaces which had been etched with hydrofluoric acid (Smoot et al., 1985). Slides and peels are deposited in The Ohio State Paleobotanical Collection under acquisition numbers 18,05418,058 .

Individual thalli are cylindrical and measure 9-12 x 50-55 Aim (FIGS. 1-6). At one end of each thallus is an isodiametric cell, measuring 8-13 fjLm diam (FIGS. 3, 4). This cell, which morphologically resembles a holdfast, attaches the thallus to a substrate (FIG. 4). The opposite end of each thallus is somewhat truncate, with a centrally located diffuse septal plug (FIG. 5) and a frill of wall material on the periphery of the tip (FIG. 6). Near the tips of several thalli are spherical to ellipsoidal spores, each averaging 9-10 $\mathrm{x}$ 12-14 jam (FIG. 6). Thalli are completely enclosed by, and attach to, the inner surface of a poorly preserved irregularly-shaped structure (FIG. 2), which we interpret as the remains of an arthropod cuticle.

Trichomycetes are predominantly endosymbiotic associates of arthropods. They often inhabit the hindgut region of organisms in several different orders, e.g., Coleoptera, Diplopoda, Diptera, Ephemeroptera, and Plecoptera. These fungi have branched or unbranched thalli that attach to the cuticles of their hosts by cellular or acellular holdfasts. Four orders of Trichomycetes are currently recognized: Harpellales, Asellariales, Eccrinales, and Amoebidiales.

Species of Eccrinales, commonly referred to as eccrinids, are often found associated with terrestrial arthropods, such as millipedes (Diplopoda) and some beetles (Coleoptera). These hosts are detritivores and are often found in environments with abundant organic debris. The typical eccrinid possesses a coenocytic thallus with septa 


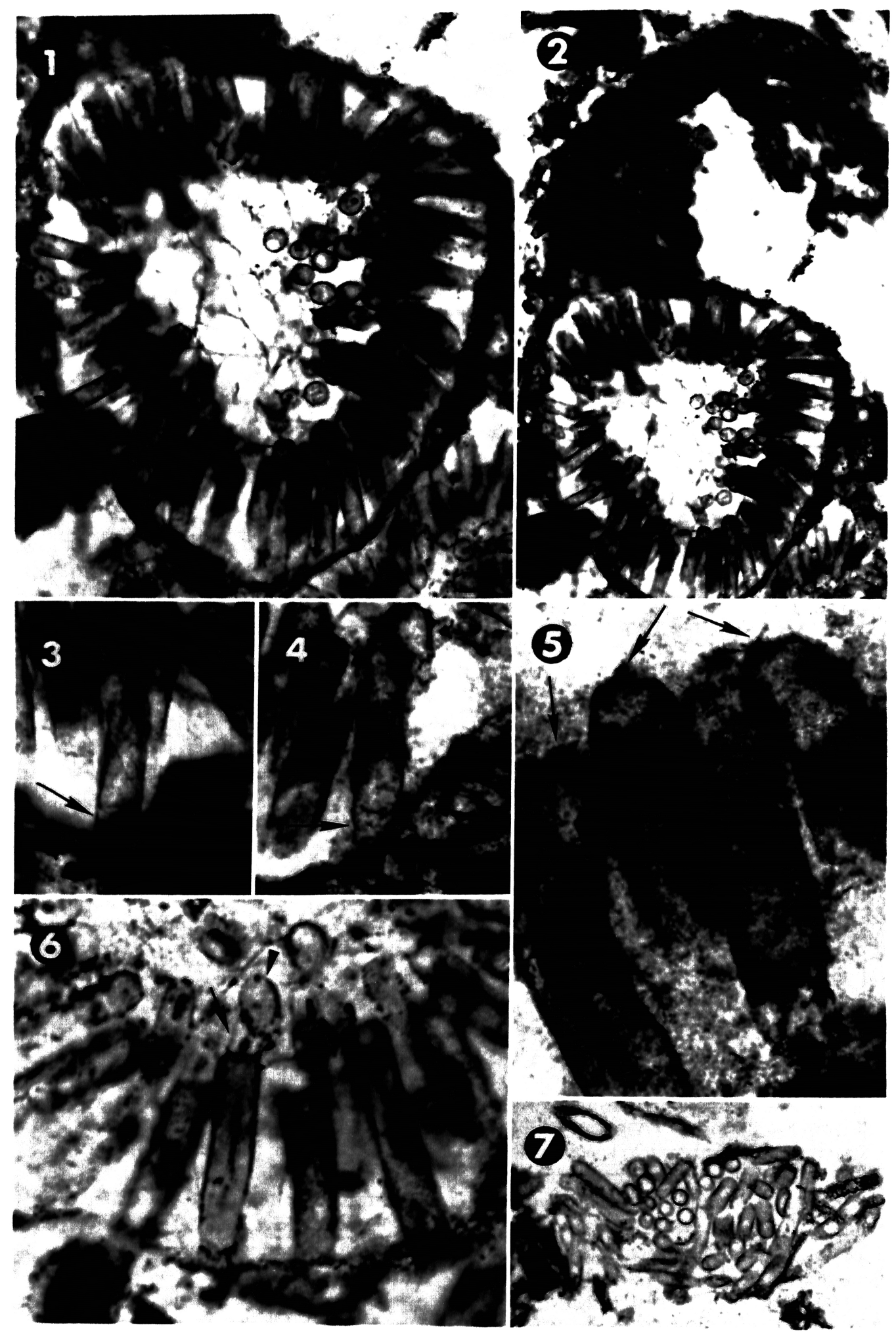


delimiting one or more sporangia in a series, each containing a single sporangiospore. Sporangiospores may be released into the alimentary tract of the arthropod by lysis of the sporangial wall and expelled into the environment where they may be ingested by other arthropods. A feature that eccrinids share with other Trichomycetes and a few other fungal groups is the possession of large septal plugs.

The fossil fungus bears several points of similarity with extant eccrinids. These include the possession of holdfasts (FIGS. 3,4), aseptate thalli (FIG. 1), spores (FIG. 6), and septal plugs (FIG. 5), all of which are comparable both in size and shape to species of the eccrinid genus Enterobryus Leidy (Lichtwardt, 1986). In addition, some thalli of the fossil bear a frill of wall remnants (FIG. 5) which may represent the remains of the lysed sporangial walls. In a previous paper clusters of cylindrical structures (FIG. 7) resembling eccrinid thalli without holdfasts and sporangia were observed and described from silicifications of the same age and collection locality (White and Taylor, 1988). These structures were interpreted as arthroconidia, but they may also represent disarticulated thalli or large secondary sporangiospores which are commonly produced by eccrinids (Lichtwardt, 1986).

Morphologically, this fossil appears to correspond closely to the Eccrinales; however, the diagnostic feature of the arthropod is lacking. A well-preserved arthropod body or cuticle would give further evidence for Trichomycete affinities of this fossil. However, host cuticles and body parts were not encountered in the silicifications bearing these fungi. Nevertheless, it is evident that arthropods or other small detritivores were abundant in the peat due to numerous fecal deposits present in the fossil matrix. The structure in which thalli are borne (FIG. 2) could be the remains of a cuticle of an arthropod hindgut. The fungus may have somehow facilitated preservation of the cuticle in areas colonized by thalli while uncolonized areas were not preserved or disarticulated during the fossilization process.
The presence of Trichomycetes in possible arthropod remains of Triassic age suggests that the symbiotic relationship between both groups is ancient and may explain the geographically widespread nature of the association between those organisms (Lichtwardt, 1986). Several of the insect hosts of Trichomycetes have been documented to occur in earlier Paleozoic sediments (Minkoff, 1983). It is probable that the present symbiotic relationship between arthropods and Trichomycetes is the result of several hundred million years of coevolution between the groups. However, whether the symbiotic relationship between arthropods or their ancestors and Trichomycetes or their ancestors was initially commensalistic, or alternately was pathogenic, is unknown. It is possible that studies of sediments where arthropods are better preserved may provide an answer to this question.

\section{ACKNOWLEDGMENTS}

The authors are grateful to Dr. Robert Lichtwardt for his advice concerning this fossil. This research was supported by National Science Foundation grant BSR8516323 .

Key Words: Eccrinales, fossil fungus, Triassic, trichomycete.

\section{LITERATURE CITED}

Davis, B., and G. A. Leisman. 1962. Further observations on Sporocarpon and allied genera. Bull. TorreyBot. Club 89: 97-109.

Dilcher, D. L. 1965. Epiphyllous fungi from Eocene deposits in western Tennessee, U.S.A. Palaeontogr. B116: 1-54.

Kidston, R., and W. H. Lang. 1921. On old red sandstone plants showing structure, from the Rhynie Chert Bed, Aberdeenshire. Trans. Roy. Soc. Edinb. 52: $855-902$.

Lichtwardt, R. W. 1986. The Trichomycetes: fungal associates of arthropods. Springer-Verlag, New York.

Minkoff, E. C. 1983. Evolutionary biology. AddisonWesley Publ. Co., Inc., Reading, Massachusetts.

Osborn, J. M., T. N. Taylor, and J. F. White, Jr. 1989. A clamp-bearing fungus from the Triassic of Antarctica. Mycologia. (In press)

FIGS. 1-7. Fossil trichomycete. 1. Palisade of thalli on inner surface of possible arthropod cuticle remains. C.B. $10,145 \mathrm{D}$ (bot-3), x300. 2. Elongate extension of possible cuticle remains (above) and thalli (below). C.B. 10,145D(bot-3), x200. 3, 4. Thalli with holdfasts (arrows). C.B. 10,145D(bot-3), x700. 5. Aseptate thalli with truncate tips and septal plugs (arrows). C.B. 10,145D(bot-3), x1300. 6. Several thalli showing sporangial wall remains (arrow) at the tip and an adjacent ellipsoidal sporangiospore (arrowhead). C.B. 10,145D(bot-14), x700. 7. Cluster of secondary sporangiospores or disarticulated thalli. C.B. $562 \mathrm{~B}($ bot-2), x224. 
Pirozynski, K. A. 1976. Fossil fungi. Annu. Rev. Phytopath. 14: 237-246.

Smoot, E. L., T. N. Taylor, and T. Delevoryas. 1985. Structurally preserved fossil plants from Antarctica. I. Antarcticycas, gen. nov., a Triassic cycad stem from the Beardmore Glacier Area. Amer. J. Bot. 72: 1410-1423.

Stubblefield, S. P., and T. N. Taylor. 1983. Studies of Paleozoic fungi. I. The structure and organi- zation of Traquairia (Ascomycota). Amer. J. Bot. 70: 387-399.

White, J. F., Jr., and T. N. Taylor. 1988. A Triassic fungus from Antarctica with possible ascomycetous affinities. Amer. J. Bot. 75: 1495-1500.

, and 1989. Triassic fungi with suggested affinities to the Endogonales (Zygomycotina). Rev. Paleobot. Palynol. (In press)

Mycologia, 81(4), 1989, pp. 646-650.

(C) 1989, by The New York Botanical Garden, Bronx, NY 10458-5126

\title{
TOXICITY AND INTERACTIONS OF SOME FUSARIUM GRAMINEARUM METABOLITES TO CATERPILLARS
}

\section{PATRICK F. DOWD}

Northern Regional Research Center, USDA-ARS, Peoria, Illinois 61604

\section{J. DAVID MILLER,' AND R. GREENHALGH}

\author{
Plant Research Centre, Agriculture Canada, Ottawa, Ontario K1A 0C6, Canada
}

\begin{abstract}
Fusarium graminearum Schwabe is a pathogen of wheat, corn and other cereals in north temperate climates. Its presence causes a reduction in quality of grains, primarily because this fungus produces mycotoxins such as the trichothecene deoxynivalenol (DON) and analogs, and zearalenone (ZEA), an estrogenic compound (Marasas et al, 1984). These metabolites can affect both the growth and reproduction of livestock, especially swine, when fed contaminated grain (Trenholm et al, 1984).

Toxic secondary metabolites of fungi are thought to be produced as a means of conserving food resources (interference competition) and/or avoiding predation (Janzen, 1977; Wicklow, 1984). Approximately 40 secondary metabolites of $F$. graminearum have been described for which no obvious ecological role has been determined (Greenhalgh et al, 1984, 1986). Concentrations of individual metabolites in naturally occurring moldy grain are normally at trace levels. As individual toxic contaminants, their toxicity should be quite low, but additive or synergistic effects of fungal metabolites may be involved in toxicity of contaminated feedstuffs (Foster et al, 1986).
\end{abstract}

Corresponding author.
Insects are also affected by fungal secondary metabolites (Wright et al, 1982), and may be selectively affected by compounds that are of relatively low toxicity to mammals (Wicklow et al, 1988). Some relatively non-toxic fungal secondary metabolites affect insects by synergistic toxicity of co-occurring toxins (Dowd, 1989).

This report concerns evaluation of some $F$. graminearum metabolites for their toxicity to fall armyworm [Spodoptera frugiperda (J. E. Smith)] and the corn earworm [Heliothis zea (Boddie)]. Both relative toxicity and toxicity of selected combinations were determined.

The metabolites DON, sambucinol (SAM), dihydroxycalonectrin (DHCAL), culmorin (CUL) and 8-hydroxycalonectrin (HCAL) (FIG. 1) were isolated and characterized according to published procedures (Greenhalgh et al, 1984, 1986). Dihydrodeoxynivalenol (DHD) was prepared by the hydrogenation of DON using a palladium/charcoal catalyst. All of these compounds, except DHD, have been found in $F$. graminearum-infected maize ears (Miller et al, 1983; Miller, unpubl.).

The metabolites were incorporated into pinto bean-based diets used to rear caterpillars (Dowd, 1987) by blending appropriate concentrations dissolved in acetone or water $(125 / \mathrm{xl})$ with un- 